\title{
Relationship between participation in leisure activities and constraints on Taiwanese breastfeeding mothers during leisure activities
}

\author{
Hsueh-wen Chow ${ }^{*}$ and Yin-Han Dong
}

\begin{abstract}
Background: Participation in leisure activities strongly associates with health and well-being. Little research has explored the relationship between participation in leisure activities and constraints on breastfeeding mothers during leisure activities. The purposes of this study are: 1) to investigate constraints on breastfeeding mothers during leisure activities and participation in leisure activities; 2 ) to investigate the differences between preferences for leisure activities and actual participation by breastfeeding mothers; 3 ) to segment breastfeeding mothers with similar patterns, using a cluster analysis based on the delineated participation in leisure activities and leisure preferences; 4 ) to explore any differences between clusters of breastfeeding mothers with respect to socio-demographic characteristics, breastfeeding behaviours and leisure constraints.
\end{abstract}

Methods: This study has a cross-sectional design using an online survey conducted among mothers having breastfeeding experiences of more than four months. The questionnaire includes demographic variables, breastfeeding behaviours, preferences for leisure activities participation, and constraints on leisure activities. Collection of data occurred between March and July 2011, producing 415 valid responses for analysis.

Results: For breastfeeding mothers, this study identifies constraints on breastfeeding related to leisure activities in addition to the three traditional factors for constraints in the model. This study demonstrates that reports of constraints related to children, family, and nursing environments are the most frequent. Breastfeeding mothers in Taiwan participate regularly in family activities or activities related to their children. Cluster analysis classified breastfeeding mothers into Action and Contemplation groups, and found that mothers within the latter group participate less in leisure activities and experienced more constraints related to breastfeeding.

Conclusions: Implications provide a developmental design for public health policies for nursing-friendly environments to increase opportunities for breastfeeding mothers to engage in leisure activities and suggest various types of activities to increase participation of that population.

\section{Background}

Considerable scientific research has proven the health benefits from breastfeeding accrue to both infants and mothers. For example, breastfeeding mothers have a lower rate of breast cancer [1,2], ovarian cancer [3-5], and osteoporosis [6]. For babies, breastfeeding has been proven to provide a protective mechanism against sudden infant death syndrome [7] and chronic diseases later in life [8]. Furthermore, these babies have lower rates of gastrointestinal and respiratory diseases $[9,10]$. In addition

\footnotetext{
* Correspondence: hwchow@mail.ncku.edu.tw

Graduate Institute of Physical Education, Health \& Leisure Studies, National Cheng Kung University, No1, University Road, Tainan 701, Taiwan
}

to the health benefits, the emotional, psychological, and societal advantages offered by breastfeeding cannot be underestimated $[11,12]$.

The prevalence of breastfeeding is increasing internationally because of the evidence of the benefits, and the declarations of the Innocenti Declaration by the World Health Organization and United Nations Children's Fund in 1990. However, the number of mothers choosing to breastfeed remains low in Taiwan. In a national study conducted in 2004, those that is breastfeeding, exclusively breastfeeding infants with only breast milk without other foods or liquids [13], in Taiwan was $33.21 \%$ when the baby was one month old, $16.93 \%$ for four-month old, and $13.13 \%$ at six-month

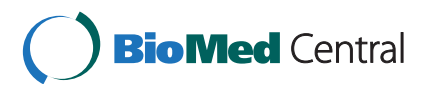


old [14]. Although these statistics increased substantially to $58.8 \%, 36.2 \%$, and $26.3 \%$, respectively, in 2010 [15], mothers in Taiwan tend to cease breastfeeding earlier than the World Health Organization's recommendation to continue exclusively breastfeeding for the first six months [16].

Although several studies in the nursing area [17] investigated the factors affecting the continuity of breastfeeding, including family and social support [18], employment status $[19,20]$, types of employment [17], sleep deprivation [21,22], and fatigue [23,24], none of these studies explored the relationship between breastfeeding and women's leisure.

Leisure is essential to well-being and health [25]. Several studies of leisure activities confirmed that leisure is a crucial factor that influences the health of women from several aspects. For example, regarding physical health, increased leisure activity can decrease the occurrence of coronary heart diseases and stroke [26], and for psychological health, participation in leisure activities can reduce stress through coping mechanisms, decreased feelings of anxiety, loneliness, and depression [27-29]. Leisure is also a vital context and channel for social support and social interactions [30,31]. In addition, since more than $20 \%$ of mothers have experienced symptoms of postpartum depression [32], leisure might be an important outlet, especially for mothers' management of depression and enhancement of health.

Despite the health benefits of leisure activities for women, participation remains lower compared to male counterparts, according to several reports [33,34]. Several reasons contribute to this phenomenon, such as lack of opportunities for learning leisure skills [35] or low socioeconomic status [34]. Traditionally, researchers of leisure activities classified three factors impeding willingness or opportunities to participate in leisure activities: intra-personal, interpersonal, and structural constraints on leisure activities. Constraints on intrapersonal activities refer to individual psychological characteristics that impede willingness to participate in leisure activities. Inter-personal constraints for participating in leisure activities are those factors involving peers or groups, such as a lack of a partner. Structural constraints are issues such as inclement weather, cost, lack of opportunity, etc. [36]. Women's leisure differs considerably from that of men's leisure, and varies in diverse life situations. While several studies investigated leisure constraints and participation in leisure activities among mothers after giving birth or those with young children, examination of specific circumstances and situations, such as experiences during breastfeeding are necessary to understand, fully, the leisure experiences and constraints for women [37].

Several barriers may relate to participation of breastfeeding mothers during leisure activities; however, scant research has investigated the relationship between participation in leisure activities and constraints on breastfeeding mothers during leisure activities. Consequently, the objectives of this study are: a) to investigate the constraints on leisure activities and participation in leisure activities experienced by breastfeeding mothers; b) to investigate the differences between preferences for leisure activities and actual participation among breastfeeding mothers; c) to examine the differences among various demographic variables relating to participation in leisure activities, and d) to identify any patterns among breastfeeding mothers, using cluster analysis based on their participation in leisure activities and leisure preferences; e) to explore differences among clusters of breastfeeding mothers with respect to socio-demographics, breastfeeding behavioural variables and leisure constraints.

\section{Method}

\section{Data collection}

Several breastfeeding mothers indicated, in focus group discussions of previous research, confining limitation from nursing schedules and the inconvenience of leaving home. Consequently, they rely on the Internet to search for information or to communicate with others. Hence, the developed questionnaire uses an online survey application, provided by Google Docs. The survey appeared as a post on seven women- and baby-related websites popular with mothers in Taiwan. Data collection occurred between March and July 2011, resulting in 531 responses. Given that the 2010 census indicates 166,886 newborn babies in Taiwan, and a breastfeeding interval of four months, postpartum, was $53.6 \%$, the targeted population for this study is 89451 . The minimum sample size required with a $95 \%$ confidence level is 382 . The analysis uses 415 responses, after eliminating invalid respondents and those not meeting the study's criteria of breastfeeding babies for more than four months. The four months breastfeeding duration represents a set inclusion criterion because a national breastfeeding survey indicated that the breastfeeding rate decreases dramatically after four months [38]. This study obtained the approval from the Institutional Review Board (IRB) from National Cheng Kung University Hospital (ER-98-281).

\section{Research instrument}

To conduct this study, an extensive literature review, and consultation with experts determined the factors that influence participation in, and constraints on, breastfeeding mothers during leisure activities. A pilot study in paper format contacted 14 local women to ensure ease of understanding and appropriateness of questions. The final questionnaire included four sections with variables for: socio-demographic data, preferences and participation in leisure activities, constraints on participation in leisure activities, and a short Taiwanese version of the International Physical Activity Questionnaire. This study analyzes data from the first three sections. 


\section{Socio-demographic and breastfeeding behaviour variables} A search of the literature indicated that age, family members, primary caregiver, educational level, employment status, number of children, age of children, breastfeeding methods, and breastfeeding duration may influence women's willingness and duration to breastfeed [39-41] or women's participation in leisure activities [33,42]. For the variable of exclusively breastfeeding, respondents responded to questions that indicate if their babies only receive breast milk, or a mix of breast milk and formula, during the duration of breastfeeding. The survey provided the four most popular practices for breastfeeding methods among Taiwanese mothers; respondents select the method that effectively described their situations. The practices are: 1) breastfeeding babies directly from their wet nurses; 2) expressing breast milk in advance and using bottles to feed babies; 3 ) alternating between feeding directly and bottle-feeding of expressed breast milk, and 4) feeding directly before bedtime, and bottle-feeding expressed milk at other times. Breastfeeding duration refers to the current length of time mothers continuously breastfeed. Since much of the behaviour or responses may change over time, the respondents were to indicate the most applicable situation at the moment of responding to the questionnaire.

\section{Participation in leisure activities}

This section is a modification of the study by Wu [43] of the typologies of women's participation in leisure activities, which includes ten types: shopping (e.g. grocery shopping), children-related (e.g. activities associated or done with children), outdoor recreation (e.g. hiking, camping), intellectual activity (e.g. language learning, going to the library), indoor exercise (e.g. bowling, badminton), entertainment (e.g. going to pubs, watching movies), social activity (e.g. clubs, religious activities, banquets), art (e.g. painting, calligraphy), competition (e.g. Taekwondo), skill-related (e.g. swimming, golfing), and others. Respondents rated, on a five-point Likert scale, their preferences (from strongly dislike to strongly like) and actual participation frequencies (never, seldom, sometimes, often and always) for each type of leisure activity.

\section{Leisure constraints}

This section's focus is constraints on leisure activities based on the conceptual model by Crawford \& Godbey [36]. The model conceptualizes three types of constraints to participation in leisure activities which are addressed above. However, the current study adds ten constraints, influencing participation in leisure activities that relate to breastfeeding. Previous literature related to women $[28,35,44]$ or breastfeeding $[14,19,20]$, and previous qualitative research identify these impediments. In the questionnaire, 37 questions use a 5-point Likert-type scale.
The possible responses ranged from 1 (strongly disagree) to 5 (strongly agree). Higher scores indicate that respondents perceive greater constraints. After factor analysis, four dimensions emerged and represent intrapersonal constraints, interpersonal constraints, structural constraints, and breastfeeding-related constraints, respectively. Each dimension has acceptable reliability with a Cronbach's alpha range above 0.8 (see Table 1). The combined scale of Cronbach's alpha was 0.931 , and calculation of the score for each dimension of constraint is a summation of the score from each question and division by the number of questions.

\section{Data analysis}

Data, imported from the Google survey used SPSS version 17.0 for analysis. Descriptive statistics represent sociodemographic characteristics of respondents, with each variable investigated. Since the ages of breastfeeding mothers in this study represents a slight oversampling of the middle age group (30-34 years old), adopting weights to adjust for the selection probabilities for that age's variable create a nationally representative sample. A bi-variate Pearson correlation and paired t-test for ten different types of leisure activities examined the correlations and differences between the preferences for leisure activities and actual participation. Conducting cluster analyses use the basis of preferences for leisure activities and actual participation of breastfeeding mothers to identify the existence of mothers' patterns for comparison of a set of demographics with participation in leisure activities and profiles of leisure constraints. Cross-tabulation examined associations; Chi-squared statistics and t-test examined differences among clusters with regard to various demographic variables, breastfeeding behaviour variables, and constrains on participation in leisure activities. For variables violating Chi-Square test assumptions (the expected count in each cell is less than 5), Fisher Exact Test using open-source language $\mathrm{R}$ allowed further examination.

In addition, the study adopts the ImportancePerformance Analysis technique [45] to compare different clusters of breastfeeding mothers' participation in leisure activities and leisure preferences for participation in ten types of leisure activities. A graphic grid displays the calculation of participation in leisure activities and leisure preferences for each activity. Cross-hairs (vertical and horizontal lines), using the mean values of participation in leisure activities and leisure preference for all subjects, represent a calculation for separating derived factors into four quadrants (see Figure 1). The two-dimensional grid displays the level of participation in leisure activities on the vertical axis from, high (top) to low (bottom) and the magnitude of preference on the horizontal axis from, high (right) to low (left). Figure 1 illustrates the resulting representation of the data that produced the four quadrants (cells). 
Table 1 Factor analysis and t-test: reliability of constraints on leisure of breastfeed directly and two clusters of breastfeeding mothers

\begin{tabular}{|c|c|c|c|c|c|c|c|c|}
\hline \multirow[b]{2}{*}{ Statement constraints } & \multirow[b]{2}{*}{$\begin{array}{c}\text { Chronbach } \\
\text { a }\end{array}$} & \multirow[b]{2}{*}{$\begin{array}{l}\text { Total } \\
(\mathrm{N}=415)\end{array}$} & \multicolumn{2}{|c|}{ Breastfeeding practice } & \multirow[b]{2}{*}{ t-value } & \multicolumn{2}{|c|}{$\begin{array}{l}\text { Clusters based on leisure } \\
\text { preference and participation }\end{array}$} & \multirow[b]{2}{*}{$\mathrm{t}$ value } \\
\hline & & & $\begin{array}{c}\text { Breastfeeding } \\
\text { directly } \\
(\mathrm{N}=177)\end{array}$ & $\begin{array}{l}\text { All other } \\
\text { practices } \\
(\mathrm{N}=238)\end{array}$ & & $\begin{array}{c}\text { Action } \\
\text { group } \\
(\mathrm{N}=231)\end{array}$ & $\begin{array}{c}\text { Contemplation } \\
\text { group } \\
(\mathrm{N}=184) \\
\end{array}$ & \\
\hline Intrapersonal constraints & .862 & 2.12 & 2.13 & 2.11 & -.240 & 2.05 & 2.20 & $-2.324^{*}$ \\
\hline Lack of interest & & 2.52 & 2.41 & 2.60 & 1.655 & 2.37 & 2.71 & $-3.019^{* *}$ \\
\hline Lack of confidence & & 1.96 & 2.00 & 1.93 & -.813 & 1.87 & 2.08 & $-2.437^{*}$ \\
\hline Afraid of going out alone & & 2.07 & 2.19 & 1.98 & -1.936 & 2.04 & 2.10 & -.503 \\
\hline Health concern & & 1.93 & 1.97 & 1.90 & -.790 & 1.91 & 1.96 & -.599 \\
\hline Difficult to get along with others & & 1.70 & 1.75 & 1.66 & -1.256 & 1.65 & 1.75 & -1.387 \\
\hline Unpleasant experience & & 1.97 & 1.99 & 1.94 & .530 & 1.93 & 2.01 & -.845 \\
\hline Not satisfied with self-body image & & 2.00 & 2.03 & 1.98 & -.486 & 1.95 & 2.08 & -1.320 \\
\hline Poor physical fitness & & 2.50 & 2.48 & 2.51 & .258 & 2.44 & 2.57 & -1.126 \\
\hline Lack of skill & & 2.41 & 2.36 & 2.44 & .701 & 2.27 & 2.59 & $-2.952^{* *}$ \\
\hline Interpersonal constraints & .887 & 2.54 & 2.54 & 2.53 & -.100 & 2.54 & 2.53 & .106 \\
\hline My family/friends oppose & & 2.15 & 2.14 & 2.15 & .055 & 2.09 & 2.22 & -1.196 \\
\hline No partner & & 2.75 & 2.76 & 2.73 & .230 & 2.72 & 2.79 & -.581 \\
\hline My partners are too busy at work & & 2.64 & 2.67 & 2.60 & .631 & 2.66 & 2.62 & .319 \\
\hline My partner are not available & & 2.26 & 2.26 & 2.26 & -.075 & 2.31 & 2.19 & 1.295 \\
\hline My partners have difficulty traveling & & 2.31 & 2.38 & 2.26 & -1.164 & 2.32 & 2.31 & .128 \\
\hline My partners do not have time & & 3.12 & 3.14 & 3.09 & -.424 & 3.10 & 3.14 & -.343 \\
\hline My partners' interests are different & & 2.69 & 2.68 & 2.69 & .142 & 2.75 & 2.61 & 1.393 \\
\hline $\begin{array}{l}\text { My partners do not have such } \\
\text { leisure skills }\end{array}$ & & 2.39 & 2.39 & 2.38 & -.040 & 2.38 & 2.40 & -.187 \\
\hline Structural constraints & .824 & 3.07 & 3.00 & 3.11 & 1.480 & 3.05 & 3.09 & -.548 \\
\hline Weather issues & & 3.23 & 3.28 & 3.20 & -.786 & 3.34 & 3.10 & $2.144^{*}$ \\
\hline Taking care of family members & & 3.89 & 3.84 & 3.94 & .955 & 3.91 & 3.87 & .395 \\
\hline Too many chores & & 3.22 & 3.10 & 3.30 & 1.753 & 3.15 & 3.29 & -1.198 \\
\hline Too much work & & 2.79 & 2.41 & 3.07 & $6.003^{* * *}$ & 2.72 & 2.89 & -1.498 \\
\hline Lack of transportation & & 2.59 & 2.65 & 2.55 & -.896 & 2.59 & 2.60 & -.030 \\
\hline Lack of information & & 2.38 & 2.34 & 2.41 & .711 & 2.32 & 2.45 & -1.300 \\
\hline Lack of money & & 2.68 & 2.79 & 2.61 & -1560 & 2.70 & 2.66 & .392 \\
\hline Too crowded and too noisy & & 3.06 & 3.03 & 3.08 & -.385 & 2.98 & 3.15 & -1.463 \\
\hline Lack of time & & 3.63 & 3.43 & 3.78 & $3.105^{* *}$ & 3.63 & 3.64 & -.104 \\
\hline Lack of space/facilities & & 3.18 & 3.18 & 3.18 & -.007 & 3.15 & 3.23 & -.696 \\
\hline Nursing-related constraints & .873 & 3.51 & 3.44 & 3.56 & 1.446 & 3.42 & 3.62 & $-2.514^{*}$ \\
\hline Concern with babies' health & & 3.42 & 3.38 & 3.44 & .506 & 3.37 & 3.47 & -.846 \\
\hline Babies too attached to mothers & & 3.76 & 3.91 & 3.65 & $-2.323^{*}$ & 3.75 & 3.78 & -.265 \\
\hline $\begin{array}{l}\text { No other family members could } \\
\text { help with taking care of the babies }\end{array}$ & & 3.00 & 3.10 & 2.92 & -1.345 & 2.92 & 3.09 & -1.303 \\
\hline $\begin{array}{l}\text { Leisure activities not appropriate } \\
\text { for children }\end{array}$ & & 3.96 & 3.94 & 3.97 & .383 & 3.95 & 3.97 & -.138 \\
\hline $\begin{array}{l}\text { Unfriendly nursing environment in } \\
\text { leisure activities place/recreation space }\end{array}$ & & 3.87 & 3.73 & 3.98 & $2.232^{*}$ & 3.75 & 4.04 & $-2.676^{* *}$ \\
\hline $\begin{array}{l}\text { Feel guilty to bother other family } \\
\text { members to take care of babies }\end{array}$ & & 3.80 & 3.67 & 3.89 & 1.970 & 3.75 & 3.86 & -1.005 \\
\hline
\end{tabular}




\begin{tabular}{|c|c|c|c|c|c|c|c|}
\hline $\begin{array}{l}\text { No or insufficient breastfeeding } \\
\text { rooms in leisure activities } \\
\text { place/recreation space }\end{array}$ & 3.78 & 3.64 & 3.89 & $2.169^{*}$ & 3.64 & 3.95 & $-3.033^{* *}$ \\
\hline $\begin{array}{l}\text { Difficulty accessing } \\
\text { breastfeeding rooms }\end{array}$ & 3.78 & 3.61 & 3.90 & $2.489^{*}$ & 2.54 & 2.90 & $-2.797^{* *}$ \\
\hline $\begin{array}{l}\text { Embarrassment being outdoors } \\
\text { and in others' views }\end{array}$ & 2.70 & 2.65 & 2.74 & .701 & 2.88 & 3.14 & $-3.110^{* *}$ \\
\hline $\begin{array}{l}\text { Traditional myths from } \\
\text { older generation }\end{array}$ & 3.00 & 2.77 & 3.17 & $3.079 * *$ & 2.86 & 3.07 & $-2.015^{*}$ \\
\hline
\end{tabular}

\section{Results}

\section{Descriptive statistics of participants}

The analyses use data from 415 valid respondents. The mean age of the respondents is $31.4( \pm 3.6)$. More than half of respondents live in the northern part of Taiwan. Approximately $14.9 \%$ of nursing mothers live with their parents, and $38.8 \%$ live with their parents-in-law. The children's mothers are the primary caregivers (78.1\%), and most of them have college degrees or higher education $(88.7 \%)$, which is slightly higher than the national census data for the reproductive-aged population in Taiwan [46]. Of respondents, 58.1\% have full-time employment; $63.4 \%$ have one child; $33.3 \%$ have two children, and $99.8 \%$ have a youngest child less than six years old. Regarding breastfeeding, $82.7 \%$ indicates breastfeed their babies only breast milk without formula, and for breastfeeding practices, $40.5 \%$ breastfeed directly; $16.6 \%$ breastfeed expressed breast milk from bottles; $31.8 \%$ adopt alternating breastfeeding, and $11.1 \%$ breastfeed directly just prior to bed time and use bottles for other times, such as during daily full-time work. The duration of breastfeeding varies; $40.2 \%$ breastfed for less than six months. A profile of detailed characteristics of respondents appears in Table 2.

\section{Constraints on leisure activities}

As shown in Table 1 , in the total column $(\mathrm{N}=415)$, breastfeeding mothers report that breastfeeding-related constraints on leisure are the most frequent encountered (Average Mean $=3.51$ ), followed by structural constraints (Average $\mathrm{M}=3.07$ ), interpersonal constraints (Average $M=2.54$ ), and intrapersonal constraints (Average $M=2.12$ ). Items such as "Leisure activities are not appropriate for children $(M=3.96)$," "Need to take care of family members $(M=3.89)$ " and "Unfriendly nursing environment during leisure activities' place/recreation space $(M=3.87)$ " are the most frequently mentioned constraints indicated. Respondents also reported significant constraints from other breastfeeding related factors, such as "feeling guilty bothering other family members to care for the baby
$(\mathrm{M}=3.80)$," "no or insufficient breastfeeding rooms in leisure activities' place/recreation space $(\mathrm{M}=3.78)$," "difficulty accessing breastfeeding rooms $(M=3.78)$," and "babies too attached to mothers $(M=3.76)$." In order to examine is there any difference of leisure constraints in terms of their breastfeeding practice. Respondents were further divided into two groups which the first group refers to breastfeeding their babies directly from wet nurse, the second group comprises feeding methods such as bottle feed with expressed milk, alternating between the breast directly and bottle with expressed milk, and directly from breast only before bedtime were combine together as all the others. Significant differences were found in the following items: "Too much work", "Lack of time", "Babies too attached to mothers", "Unfriendly nursing environment in leisure activities place/recreation space", "No or insufficient breastfeeding rooms in leisure activities place/recreation space", "Difficulty accessing breastfeeding rooms", and "Traditional myths from older generation" (Table 1).

Preferences for leisure and participation in leisure activities The descriptive statistics with means and standard deviations of breastfeeding mothers' leisure activity preferences and participation appear in Table 3, clarifying the differences between preferences for leisure activities or desire for leisure and actual participation in various types of leisure activities. The results reveal that most breastfeeding mothers in Taiwan participate in family activities or activities related to their children than other types of activities. The lowest preference and actual participation activities are skill-related and competitive. Although significant correlation coefficients in Table 3 reveal that participation is consistent with preferences (Pearson $\mathrm{r}$ ranges from 0.279 to 0.488 ), significant statistical differences appear between preferences and actual participation from paired t-tests for all ten types of leisure activities. The preferences for leisure activities of breastfeeding mothers are significantly higher than their actual participation. 

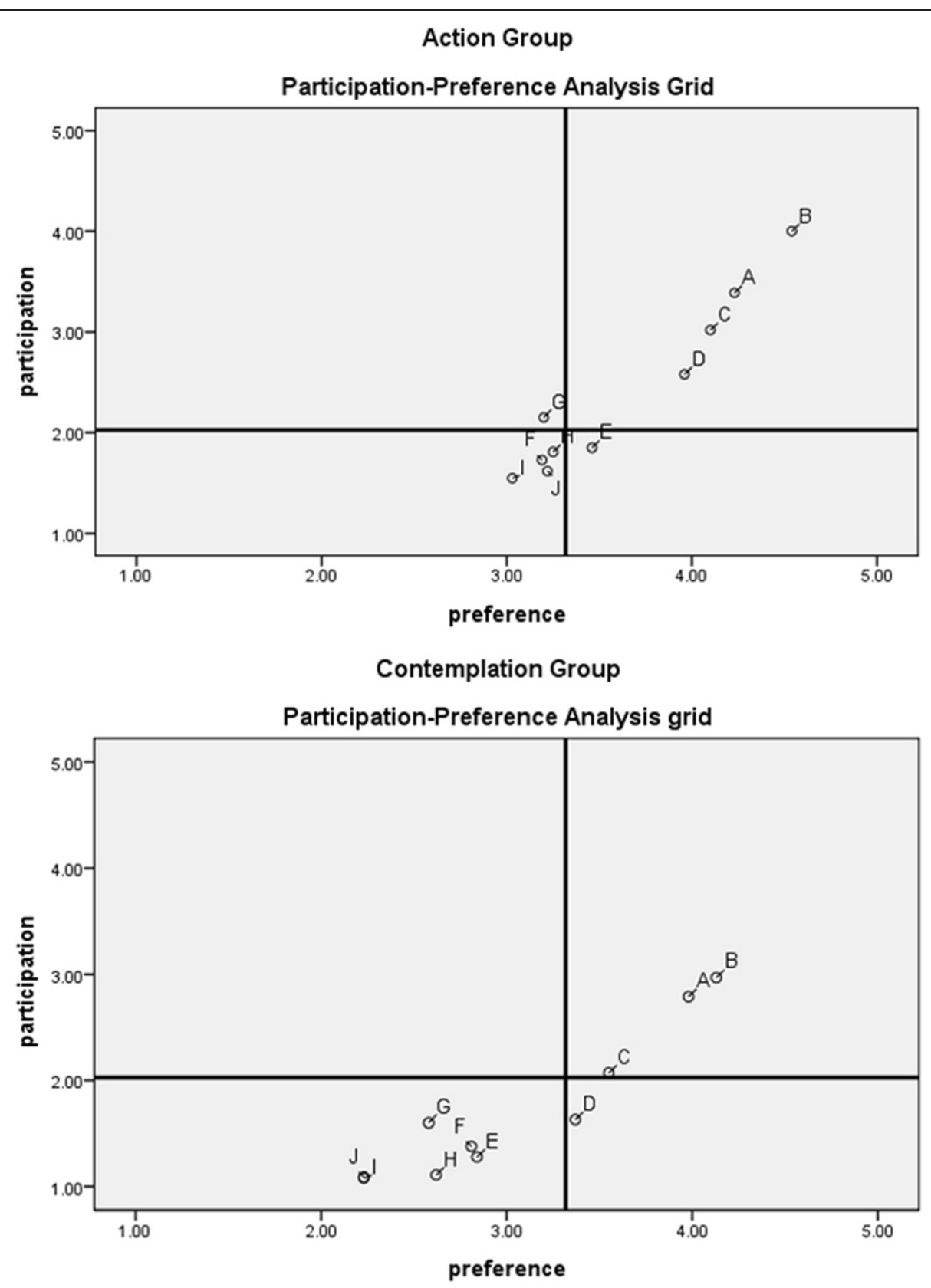

A-shopping, B-children-related activity, C-outdoor recreation, D-intellectual activity, E-indoor exercise activity $\mathrm{F}$ - entertainment, $\mathrm{G}$ - social activity, $\mathrm{H}$-art, I-competition activity, J-skill-related activity

Figure 1 Leisure preference and leisure participation analysis grid of breastfeeding mothers in action group and contemplation group.

\section{Classification of breastfeeding mothers}

Classification of breastfeeding mothers based on preferences for leisure and participation in leisure activities employed cluster analysis, which identified two groups. The first group are those with a high level of preferences for leisure and participation in leisure activities. The second group of mothers represents those with high preference, but low levels of actual participation in leisure activities. Thus, the first group is named as the Action group, and the second group is named as the Contemplation group, since the first group participated in leisure activities, and the second group, despite high inclination displayed a low rate of participation in leisure activities. 
Table 2 Characteristics of respondents

\begin{tabular}{|c|c|c|}
\hline \multirow[t]{2}{*}{ Variable } & \multicolumn{2}{|c|}{ Total $(\mathrm{N}=415)$} \\
\hline & $\%$ & $\mathrm{~N}$ \\
\hline \multicolumn{3}{|l|}{ Ages } \\
\hline $21-25 y r s$ & 6.0 & 25 \\
\hline $26-30 y r s$ & 34.0 & 141 \\
\hline $31-35 y r s$ & 45.3 & 188 \\
\hline $36-40 y r s$ & 9.9 & 41 \\
\hline $40+$ and over & 1.0 & 4 \\
\hline Unknown & 3.9 & 16 \\
\hline \multicolumn{3}{|l|}{ Education level } \\
\hline Junior high school & 0.7 & 3 \\
\hline Senior high school & 10.6 & 44 \\
\hline Vocational/college degree & 68.9 & 286 \\
\hline Graduate school or above & 19.8 & 82 \\
\hline \multicolumn{3}{|l|}{ Job } \\
\hline Full-time & 58.1 & 241 \\
\hline Part-time & 3.9 & 16 \\
\hline Contracted & 1.0 & 4 \\
\hline Unemployed & 37.1 & 154 \\
\hline \multicolumn{3}{|l|}{ Number of children } \\
\hline One & 63.4 & 263 \\
\hline Two & 33.3 & 138 \\
\hline Three & 3.1 & 13 \\
\hline Four & 0.2 & 1 \\
\hline \multicolumn{3}{|l|}{ Age of youngest children } \\
\hline $0-6 y r s$ & 99.8 & 414 \\
\hline $7-12 y r s$ & 0.2 & 1 \\
\hline \multicolumn{3}{|l|}{ Family member } \\
\hline Parents & 14.9 & 62 \\
\hline Parents-in -law & 38.8 & 161 \\
\hline Spouse & 91.1 & 378 \\
\hline Children & 91.6 & 380 \\
\hline Others & 12.3 & 51 \\
\hline \multicolumn{3}{|l|}{ Caregiver } \\
\hline Parents & 17.3 & 72 \\
\hline Parents-in -law & 22.4 & 93 \\
\hline Myself & 78.1 & 324 \\
\hline Spouse & 20.0 & 83 \\
\hline Babysitter & 16.9 & 70 \\
\hline Others & 2.4 & 10 \\
\hline \multicolumn{3}{|l|}{ Exclusively breastfeeding } \\
\hline Mix breast milk and others & 17.3 & 72 \\
\hline Only breast milk & 82.7 & 343 \\
\hline \multicolumn{3}{|l|}{ Breastfeeding practices } \\
\hline From breast directly & 40.5 & 168 \\
\hline
\end{tabular}

Table 2 Characteristics of respondents (Continued)

\begin{tabular}{lcc}
\hline Bottle feed with expressed milk & 16.6 & 69 \\
$\begin{array}{l}\text { Alternating between directly feeding and } \\
\text { expressed milk from bottles }\end{array}$ & 31.8 & 132 \\
Directly from breast only before bedtime & 11.1 & 46 \\
Breastfeeding duration & & \\
4-6 month & 40.2 & 167 \\
7-12 month & 34.2 & 142 \\
13-18 month & 15.4 & 64 \\
19-24 month & 5.8 & 24 \\
25-36 month & 4.3 & 18 \\
\hline
\end{tabular}

Differences between the action and contemplation group Investigation of factors contributing to differences in the classifications of Contemplation and Action groups, used Crosstab Chi-square, and the results appear in Table 4. A significant difference exists between Action and Contemplation groups regarding their breastfeeding practices. Women in the Action group have a significantly higher percentage of instances for breastfeeding their babies directly than do those in the Contemplation group $\left(x^{2}=9.004, d f=3, p=0.029\right)$. No significant differences exist among age groups, education levels, working status, exclusively breastfeeding, and duration in comparison to leisure activity for the Contemplation and Action groups.

\section{Constraints to participation in leisure activities among action and contemplation groups}

Independent $t$-test investigated differences of constraints to participating in leisure activities between Action and Contemplation groups. Results reveal that the Contemplation group perceive significantly higher constraints from nursing-related $(\mathrm{t}=-2.514, p=0.012)$ and intrapersonal leisure constraints $(\mathrm{t}=-2.324, p=0.021)$. (See Table 1).

\section{Analysis of various leisure activities}

As seen in Figure 1, ten types of leisure activities create plots for a preference-participation grid for Action and Contemplation groups. Both Action and Contemplation groups have similar perceptions toward children-related activities, shopping activities, and outdoor recreation, all represented in the high-preference and highparticipation quadrant (top-right); entertainment, art, competitive activities, and skill-related activities represent the low-preference and low-participation quadrant (bottom-left) for both groups. However, intellectual activity, indoor exercise activities, and social activities have different perception for the Action group and the Contemplation group. 
Table 3 Mean differences in leisure participation and leisure preference in various leisure activities

\begin{tabular}{|c|c|c|c|c|c|}
\hline Leisure activities & Participation/preference & Mean $(\mathrm{N}=415)$ & S. D. & $t$ value & Pearson $r$ \\
\hline \multirow[t]{2}{*}{ Shopping } & Leisure participation & 3.07 & .903 & $-23.083^{* * *}$ & $.365^{* * *}$ \\
\hline & Leisure preference & 4.10 & .683 & & \\
\hline \multirow[t]{2}{*}{ Children-related activity } & Leisure participation & 3.46 & 1.176 & $-17.236^{* * *}$ & $.488^{* * *}$ \\
\hline & Leisure preference & 4.33 & .665 & & \\
\hline \multirow[t]{2}{*}{ Outdoor recreation } & Leisure participation & 2.53 & 1.064 & $-23.209 * * *$ & $279^{* * *}$ \\
\hline & Leisure preference & 3.83 & .799 & & \\
\hline \multirow[t]{2}{*}{ Intellectual activity } & Leisure participation & 2.07 & .939 & $-32.177^{* * *}$ & $.323^{* * *}$ \\
\hline & Leisure Preference & 3.67 & .802 & & \\
\hline \multirow[t]{2}{*}{ Indoor exercise activity } & Leisure participation & 1.55 & .751 & $-33.926^{* * *}$ & $328^{* * *}$ \\
\hline & Leisure preference & 3.18 & .915 & & \\
\hline \multirow[t]{2}{*}{ Entertainment } & Leisure participation & 1.58 & .750 & $-28.004^{* * *}$ & $.333^{* * *}$ \\
\hline & Leisure preference & 3.02 & 1.015 & & \\
\hline \multirow[t]{2}{*}{ Social activity } & Leisure participation & 1.88 & .976 & $-19.481^{* * *}$ & $.432^{* * *}$ \\
\hline & Leisure preference & 2.87 & .971 & & \\
\hline \multirow[t]{2}{*}{ Art } & Leisure participation & 1.44 & .752 & $-33.252^{* * *}$ & $.362^{* * *}$ \\
\hline & Leisure preference & 2.94 & .866 & & \\
\hline \multirow[t]{2}{*}{ Competition activity } & Leisure participation & 1.31 & .596 & $-31.018^{* * *}$ & $.383^{* * *}$ \\
\hline & Leisure preference & 2.65 & .917 & & \\
\hline \multirow[t]{2}{*}{ Skill-related activity } & Leisure participation & 1.35 & 649 & $-29.369^{* * *}$ & $.373^{* * *}$ \\
\hline & Leisure preference & 2.74 & .933 & & \\
\hline \multirow[t]{2}{*}{ All } & Leisure participation & 2.02 & .497 & $-47.455^{* * *}$ & $.338^{* * *}$ \\
\hline & Leisure preference & 3.33 & .485 & & \\
\hline
\end{tabular}

Note: ${ }^{* * *} \mathrm{p}<.001$

\section{Discussion}

\section{Leisure constraints faced by breastfeeding mothers}

The main purpose of this study is investigation of constraints breastfeeding mothers confront restricting participation in leisure activities. First, a factor structure of the constraints' scale reveals that, in addition to the traditional three factors of constraints on leisure (intrapersonal, interpersonal, and structural constraints), a fourth factor, breastfeeding-related constraints, occur. This result presents a unique and specific constraint for breastfeeding mothers in daily life. Although several breastfeeding-related studies disclosed barriers influencing breastfeeding, none explored pursuing leisure. The uncovered factors result in limited and fragmented leisure time for breastfeeding mothers. The current study also demonstrates that constraints related to children, family, and nursing environments are, reportedly, the most intensively experienced.

Compared to men, women's life stages and constraints, which may change over a lifespan considerably influence leisure activities [37]. In particular household obligations and family commitments, usually limit women's time for leisure [47]. Mothers of young children tend to "put others' wellbeing first" [48] instead of their own leisure needs. Although these family roles and obligations appear for consideration in many other studies of women and leisure $[49,50]$, a lack of a sense of entitlement to leisure [51] is significantly intense for nursing mothers who feel responsible because their babies' dependence on mothers for nourishment, particularly for breastfeeding mothers with children under six months old.

An unfriendly environment is another significant barrier for nursing mothers that inhibits participation in leisure activities. Several public and recreational areas do not have adequate nursing environments, which causes inconvenience for breastfeeding or to expressing milk. In 2008, Wu et al. interviewed Taiwanese nurses to gain insight into their breastfeeding experiences and found that outings are inconvenient most of the time, and embarrassment arises from breastfeeding in public; hence, the preference is to remain at home. If going outdoors with children, vehicles become mobile breastfeeding and milk-expressing "rooms" [17]. Breastfeeding in public has a privacy component due to limited nursing rooms available on-site at public leisure or recreational venues. 
Table 4 Crosstabs of action group and contemplation group for various demographic and breastfeeding behavioural variables

\begin{tabular}{|c|c|c|c|c|}
\hline \multirow[t]{2}{*}{ Variable } & \multicolumn{2}{|c|}{$\begin{array}{l}\text { Action } \\
\text { group }\end{array}$} & \multicolumn{2}{|c|}{$\begin{array}{l}\text { Contemplation } \\
\text { group }\end{array}$} \\
\hline & $\%$ & $\mathbf{N}$ & $\%$ & $\mathbf{N}$ \\
\hline Ages & \multicolumn{2}{|c|}{$n=226$} & \multicolumn{2}{|c|}{$n=176$} \\
\hline $21-25 y r s$ & 11.1 & 25 & 13.6 & 24 \\
\hline 26-30yrs & 36.7 & 83 & 33.0 & 58 \\
\hline $31-35 y r s$ & 38.5 & 87 & 39.8 & 70 \\
\hline $36-40 y r s$ & 12.8 & 29 & 12.5 & 22 \\
\hline \multirow[t]{2}{*}{$40+$ and over } & 0.9 & 2 & 1.1 & 2 \\
\hline & \multicolumn{4}{|c|}{$p$-value $=0.8918$} \\
\hline Education level & \multicolumn{2}{|c|}{$n=231$} & \multicolumn{2}{|c|}{$n=184$} \\
\hline Junior high school & 0 & 0 & 1.6 & 3 \\
\hline Senior high school & 12.6 & 29 & 13.0 & 24 \\
\hline Vocational/college degree & 71.0 & 164 & 64.1 & 118 \\
\hline \multirow[t]{2}{*}{ Graduate school or above } & 16.5 & 38 & 21.2 & 39 \\
\hline & \multicolumn{4}{|c|}{$p$-value $=0.1278$} \\
\hline Job & \multicolumn{2}{|c|}{$\mathrm{n}=130$} & \multicolumn{2}{|c|}{$n=117$} \\
\hline Full-time & 93.1 & 121 & 92.3 & 108 \\
\hline Part-time & 6.2 & 8 & 6.0 & 7 \\
\hline \multirow[t]{2}{*}{ Contracted } & 0.8 & 1 & 1.7 & 2 \\
\hline & \multicolumn{4}{|c|}{$p$-value $=0.9173$} \\
\hline Exclusively breastfeeding & \multicolumn{2}{|c|}{$n=231$} & \multicolumn{2}{|c|}{$n=184$} \\
\hline Only breast milk & 85.3 & 197 & 81.0 & 149 \\
\hline \multirow[t]{2}{*}{ Mix breast milk and others } & 14.7 & 34 & 19.0 & 35 \\
\hline & \multicolumn{4}{|c|}{$\chi^{2}=1.368 \mathrm{~d} f=1$} \\
\hline Breastfeeding practice & \multicolumn{2}{|c|}{$n=232$} & \multicolumn{2}{|c|}{$n=185$} \\
\hline From breast directly & 48.7 & 113 & 34.6 & 64 \\
\hline Bottle feed with expressed milk & 13.4 & 31 & 20.0 & 37 \\
\hline $\begin{array}{l}\text { Alternating between the breast } \\
\text { directly and bottle with expressed milk }\end{array}$ & 28.4 & 66 & 34.0 & 63 \\
\hline \multirow{2}{*}{$\begin{array}{l}\text { Directly from breast only } \\
\text { before bedtime }\end{array}$} & 9.5 & 22 & 11.4 & 21 \\
\hline & \multicolumn{4}{|c|}{$\chi^{2}=9.004^{*} \mathrm{~d} f=3$} \\
\hline Breastfeeding duration & \multicolumn{2}{|c|}{$N=231$} & \multicolumn{2}{|c|}{$N=185$} \\
\hline 4- less or equal to 6 month & 39.8 & 92 & 44.9 & 83 \\
\hline 7-12 month & 33.8 & 78 & 31.9 & 59 \\
\hline 13-18 month & 15.2 & 35 & 14.6 & 27 \\
\hline 19-24 month & 7.3 & 17 & 4.3 & 8 \\
\hline \multirow[t]{2}{*}{ 25-36 month } & 3.9 & 9 & 4.3 & 8 \\
\hline & \multicolumn{4}{|c|}{$\chi^{2}=2.371 \mathrm{~d} f=4$} \\
\hline
\end{tabular}

Note: ${ }^{*} \mathrm{p}<.05$.
Leisure preferences, participation in leisure activities, and comparison between action and contemplation groups

The ranking of leisure preferences for breastfeeding mothers are consistent with their participation in leisure activities. Most nursing mothers in Taiwan participate in more family activities or activities related to their children. The least preference and participation types are competitions and skills-related activities. The order suggests that women prioritize their time and activities to relate to children and families instead of individually oriented or skill-level activities. Further analysis from this study reveals that respondents' preferences for leisure are considerably higher than their participation in all ten types of leisure activities. The difference between preferences or desire for leisure and actual participation re-confirms that constraints on leisure intervene.

From mapping of preferences for leisure and participation in leisure activities, for both Action and Contemplation groups, those activities strongly tied to family obligations, such as children-related activities, shopping (e.g. grocery shopping, baby -clothing shopping), and out-door recreation (e.g. taking children to a park) represent high-preference and high-participation activities. This result is consistent with many studies' notions that women's leisure typically involves work, caring for or, in the company of others, fulfilling roles as wives or mothers [52]. These activities may also represent a self-selected filter for activities because women choose leisure mainly based on a combination of opportunities available, as suggested by Colley [53].

A more in-depth analysis of the activities falling in the low-preference and low-participation quadrant (bottom-left), such as competitive or skill-related activities may also reflect the traditional concepts of gender that women avoid active forms of leisure or activities requiring skills. Conventional perceptions discourage women's engaging in independent or active leisure and, perhaps lack opportunities to learn [52]. Altogether, the similar patterns illustrated for both top-right and bottom-left activities may relate to women's ethic of care [51] in that, although they desire personal time to enjoy leisure, they feel guilty; according to Shaw, "Women may adjust their expectations to fit the reality of their lives" (p11) [54].

Interestingly, some activities appear in different quadrants. Intellectual activities, such as visiting museums or a library, and learning a language, have high degree of preference for both groups, but only the Action group demonstrates high participation. The Action group manages to attend these activities despite juggling time and obligations for feeding babies. Both groups report low participation in indoor exercise, but Action group perceives a higher preference. Explanation for this finding may arise from research suggesting breastfeeding can easily cause fatigue $[55,56]$, but the Action group shows a desire to 
avoid lethargy. Actually, many women with young children do not meet the guidelines for physical activity to achieve health benefits [57]. Social activities, such as attending clubs, religious services, and participating in formal banquets, rate low in preference for both groups, but the Action group reveals a higher participation rate. Social activities listed in the questionnaire are more likely to be formal, which many breastfeeding women consider inappropriate if accompanied by children and breastfeed if necessary. The Action group might be those who are more out-going and participate in activities even if disagreeable.

\section{Comparison of demographic backgrounds, breastfeeding behaviours, and constraints on leisure: differences between action and contemplation groups}

No significant differences appear in terms of breastfeeding mothers' ages, educational levels, working status, and some breastfeeding behaviours. However, a higher percentage of women in the Action group adopted breastfeeding their babies directly, compared to other practices, such as bottle feeding with expressed milk, alternating between breastfeeding directly and bottle feeding with expressed milk, or directly feeding from the breast only before bedtime. The results also demonstrate that the Contemplation group has a significantly higher degree of constraint than the Action group for intrapersonal and breastfeedingrelated leisure constraints. The explanation of these results could be that mothers, who adopted other breastfeeding practices other than directly breastfeeding, have more chores such as pumping breast milk, freezing and reheating milk, washing bottles, etc. These tasks might take more time from mothers' hectic lifestyles, which cause more stress for these groups of mothers and prevents them from participating in leisure activities and creates and unwillingness to leave home because not many nursingfriendly spaces exist in the public. Although different breastfeeding practices have not received significant attention in earlier breastfeeding-related research, recently, some articles began to debate the influence of different breastfeeding practices on women's breastfeeding behaviour [58-60]. The influence of different breastfeeding practices on women's perceptions of leisure warrant further investigation. Furthermore, many women lack interests or skills necessary for participation in leisure activities, which may be due to a lack of previous involvement in leisure activities. Many women perceive participation in leisure activities to be constrained because they have a narrow range of activities deemed appropriate for women or girls. The Contemplation group seems to suffer more severely in this regard. Breastfeeding-related constraints on leisure refer to those psychological states that are specific to breasting mothers, and environmental barriers for nursing. Since breastfeeding offers unique bonding between mothers and their babies, occasionally breastfeeding mothers may hesitate to separate from their babies because the mother is the only providers of nutrients or comfort. Mothers tend to abandon participation in leisure activities when experiencing internal conflict between personal fulfillment and obligation to the needs of others [61,62]. The Contemplation group might feel guilt/anxiety when engaging in personal leisure rather than in fulfilling obligations to others. They may lack a sense of entitlement for personal leisure [51]. Another crucial issue is nursing environment. Current literature related to nursing environments only focuses on work-sites [17,63-65]; limited attention accrues to providing adequate nursing environments for breastfeeding mothers in leisure/recreation settings, a crucial space for breastfeeding mothers' participation in leisure activities, social participation, or time with children and family outside the home. Inferior facilities and services for breastfeeding mothers and inadequate promotion of breastfeeding in the public all relate to non-participation in leisure by breastfeeding mothers.

\section{Conclusion}

This study indicates the constraints on leisure activities limit Taiwanese breastfeeding mothers' access to participation in leisure activities, or preferences for actual participation in leisure activities. The study provides an awareness of constraints on leisure activities for breastfeeding mothers, and these issues have rare investigation. Several of these constraints on leisure are unlikely to be overcome by individuals alone.

The success of cluster analysis in identifying two groups of breastfeeding mothers with encountered constraints on leisure suggests that the approach may be useful in public health promotion using different strategies to enhance breastfeeding mothers' leisure activities and participation. Breastfeeding is a challenge and requires support from family or health providers, and also society. The identification of specific constraints for breastfeeding mothers can provide evidence when vocalizing the effects of encountered constraints and empower them to negotiate rights for leisure. In addition, the data also offer insights for effective planning, provision, and management of leisure services and public health.

\section{Limitation of the study and directions for future studies}

Several limitations require acknowledgement. First, the study only investigates constraints on leisure from mothers with breastfeeding experience. Since most other studies only focus on mothers with young children without specifying breastfeeding [47,56], this study could not yield differences between breastfeeding-mothers and non-breastfeeding mothers with regard to participation in leisure activities and constraints on leisure. Second, mothers might alter their participation in leisure activities or encounter different constraints during various stages of 
breastfeeding practice. The impact of breastfeeding on a mother's participation in leisure activities and constraints on leisure might have different degrees of influence. Indepth qualitative research is necessary to explore these changes. Next, the study utilizes an online survey, which may induce a bias for those with higher educational status than the general reproductive population. Finally, the results of this study may be subject to cultural interpretations since it is exclusive to Taiwan. Since several leisure experiences and constraints relate to an individual's social contexts [51], perhaps a noteworthy determination would be identifying any differences occurring in constraints on leisure confronted by nursing mothers in other settings. For example, a comparative study can interview mothers originally from Taiwan, but live in another country. Another study may examine the differences in constraint on leisure for breastfeeding mothers of various countries or ethnicities. Considerable knowledge regarding the unique situations that breastfeeding mothers face with regard to leisure activities is not available. By understanding these phenomena, offering a superior quality of life and improving the health of breastfeeding mothers and their families is possible.

\section{Competing interests}

The authors declare that they have no competing interests.

\section{Authors' contributions}

HWC conceived the design of the study and drafted the manuscript. YHD collected the data and analyzed the data. Both authors have read and approved the final manuscript.

\section{Acknowledgement}

This research was funded by National Science Council in Taiwan (99-2410-H006-096). The authors are grateful to all the breastfeeding mothers who have provided responses for this study.

Received: 8 March 2012 Accepted: 23 April 2013

Published: 30 April 2013

\section{References}

1. Newcomb PA, Storer BE, Longnecker MP, Mittendorf R, Greenberg ER, Clapp RW, Burke KP, Willett WC, MacMahon B: Lactation and a reduced risk of premenopausal breast cancer. New Engl J Med 1994, 330(2):81-87.

2. Chilvers C: Breast feeding and risk of breast cancer in young women. Brit Med J 1993, 307(6895):17-20.

3. Gwinn ML, Lee NC, Rhodes PH, Layde PM, Rubin GL: Pregnancy, breast feeding, and oral contraceptives and the risk of epithelial ovarian cancer. J Clin Epidemiol 1990, 43(6):559-568.

4. Hartge P, Schiffman MH, Hoover R, McGowan L, Lesher L, Norris HJ: A case-control study of epithelial ovarian cancer. Am J Epidemiol 1989, 161(1):10-16.

5. Schneider A 2nd: Risk factor for ovarian cancer. New Engl J Med 1987 317(8):508.

6. Blaauw R, Albertse EC, Beneke T, Lombard CJ, Laubscher R, Hough FS: Risk factors for the development of osteoporosis in a South African population. S Afr Med J 1994, 84:328-332.

7. Vennemann MM, Bajanowski T, Brinkmann B, Jorch G, Yucesan K, Sauerland C, Mitchell EA, Grp GS: Does breastfeeding reduce the risk of sudden infant death syndrome? Pediatrics 2009, 123(3):e406-e410.

8. Martin RM, Holly JMP, Smith GD, Ness AR, Emmett P, Rogers I, Gunnell D: Could associations between breastfeeding and insulin-like growth factors underlie associations of breastfeeding with adult chronic disease? The avon longitudinal study of parents and children. Clin Endocrino 2005, 62(6):728-737.

9. Kramer MS, Kakuma R: The optimal duration of exclusive breastfeeding. Ad Exp Med Biol 2004, 554:63-77.

10. Chantry CJ, Howard CR, Auinger P: Full breastfeeding duration and associated decrease in respiratory tract infection in US children. Pediatrics 2006, 117(2):425

11. American Academy of Pediatrics, American College of Obstetricians and Gynecologists: Breastfeeding handbook for physicians. Grove Village, IL; 2006.

12. Horta BL, Bahl R, Martinés JC, Victora CG: Evidence on the long-term effects of breastfeeding: Systematic reviews and meta-analysis. Geneva, Switzerland: World Health Organization; 2007:1-52.

13. World Health Organization: Indicators for assessing infant and young child feeding practices: conclusions of a consensus meeting held 6-8 November 2007 in Washington D.C., USA. Geneva, Switzerland; 2008.

14. Kuo SC, Lin KC, Li CY, Gau ML, Chen YL, Cheng CH: Rates of breastfeeding and associated factors in Taiwan. Taipei: Bureau of Health Promotion Department of Health, R.O.C.(Taiwan); 2004.

15. Breastfeeding rate in Taiwan. http://www.bhp.doh.gov.tw/breastfeeding/ 02qna_01.htm.

16. Kramer MS, Kakuma R: The optimal duration of exclusive breastfeeding: A systematic review. Geneva, Switzerland: Department of Nutrition for Health and Development, Department of Child and Adolescent Health and Development. World Health Organization; 2001.

17. Wu CH, Kuo SC, Lin HR: Breastfeeding experiences of Taiwan nurses on rotational shifts. JNR 2008, 16(4):297-306.

18. Huang YC: Life experiences of multipara with first time long-term breastfeeding. Taipei: National Taipei College of Nursing; 2006.

19. Bourgoin G, Lahaie NR, Rheaume B, Berger M, Dovigi C, Picard L, Sahai V: Factors influencing the duration of breastfeeding in the Sudbury region. C J Public Healt 1997, 88(4):238-241.

20. Rempel LA, Rempel JK: Partner influence on health behavior decisionmaking: Increasing breastfeeding duration. J Soc Pers Relat 2004, 21(1):92-111.

21. Foxman B, D'Arcy H, Gillespie B, Bobo JK, Schwartz K: Lactation mastitis: Occurrence and medical management among 946 breastfeeding women in the United States. Am J Epidemiol 2002, 155(2):103-114.

22. Doan T, Gardiner A, Gay CL, Lee KA: Breast-feeding increases sleep duration of new parents. J Perinat Neonat Nur 2007, 21(3):200-206.

23. Cloherty M, Alexander J, Holloway I: Supplementing breast-fed babies in the UK to protect their mothers from tiredness or distress. Midwifery 2004, 20(2):194-204.

24. Olsson A, Lundqvist M, Faxelid E, Nissen E: Women's thoughts about sexual life after childbirth: focus group discussions with women after childbirth. Scand J Caring Sci 2005, 19(4):381-387.

25. Payne L: Relations between leisure, health, and wellness. In Leisure, Health, and Wellness: Making the connections. Edited by Payne L, Ainsworth B, Godbey G. State College, PA: Venture Publisher; 2010:21-29.

26. U.S. Department of Health and Human Services: Physical Activity and Health: A Report of the Surgeon General. Atlanta, GA: US Department of Health and Human Services, Centers for Disease Control and Prevention, National Center for Chronic Disease Prevention and Health Promotion; 1996.

27. Klitzing SW: Women living in a homeless shelter: Stress, coping and leisure. J Leisure Res 2004, 36:483-513.

28. Hall DT: A model of coping with role conflict: The role behavior of college educated women. Admin Sci Quart 1972, 17(4):471-486.

29. Iwasaki Y: Counteracting stress through leisure coping: A prospective health study. Psychol Health Med 2006, 11(2):209-220.

30. Coleman D, Iso-Ahola SE: Leisure and health: The role of social support and self-determination. J Leisure Res 1993, 25:111-111.

31. Lloyd KM, Auld CJ: The role of leisure in determining quality of life: Issues of content and measurement. Soc Indic Res 2002, 57(1):43-71.

32. Miller L: Postpartum depression. JAMA 2002, 287(6):762-765

33. Sternfeld B, Ainsworth BE, Quesenberry CP Jr: Physical activity patterns in a diverse population of women. Prev Med 1999, 28(3):313-323.

34. Azevedo M, Araújo C, Reichert F, Siqueira F, da Silva M, Hallal P: Gender differences in leisure-time physical activity. Int J Public Health 2007, 52(1):8-15.

35. Flintoff A, Scraton S: Stepping into active leisure? Young women's perceptions of active lifestyles and their experiences of school physical education. Sport Educ Soc 2001, 6(1):5-21. 
36. Crawford DW, Jackson EL, Godbey G: A hierarchical model of leisure constraints. Leisure Sci 1991, 13(4):309-320.

37. Henderson KA: Broadening an understanding of women, gender and leisure. J Leisure Res 1994, 26(1):1-7.

38. Telephone survey of breastfeeding rate and its associated factors in Taiwan. http://www.bhp.doh.gov.tw/breastfeeding/02ana_01.htm.

39. Haughton J, Gregorio D, Pérez-Escamilla R: Factors associated with breastfeeding duration among Connecticut special supplemental nutrition program for women, infants, and children (WIC) participants. J Hum Lact 2010, 26(3):266-273.

40. Bosnjak AP, Grguric J, Stanojevic M, Sonicki Z: Influence of sociodemographic and psychosocial characteristics on breastfeeding duration of mothers attending breastfeeding support groups. $J$ Perinat Med 2009, 37(2):185-192.

41. Johnston ML, Esposito N: Barriers and facilitators for breastfeeding among working women in the United States. J Obstet Gynaecol 2007, 36(1):9-20.

42. Gómez LF, Mateus JC, Cabrera G: Leisure-time physical activity among women in a neighbourhood in Bogotá, Colombia: Prevalence and sociodemographic correlates. Cad Saude Publica 2004, 20(4):1103-1109.

43. Wu C: A correlational study on role conflict, leisure constraints, and leisure activity participating toward the tourism industry of career women. Chiayi County Nanhua University; 2002.

44. Frederick CJ, Shaw SM: Body image as a leisure constraint: Examining the experience of aerobic exercise classes for young women. Leisure Sci 1995, 17(2):57-73.

45. Martilla JA, James JC: Importance-performance analysis. J Mark 1977, 44(1):77-79.

46. Department of Statistics, Ministry of Interior: Report of education status for people above 15 years old, 2012 week 13. 2012. http://sowf.moi.gov.tw/stat/ month/list.htm.

47. Shaw SM: Gender and leisure: Inequality in the distribution of leisure time. J Leisure Res 1985, 17(4):266-282.

48. Arab-Moghaddam N, Henderson KA, Sheikholeslami R: Women's leisure and constraints to participation: Iranian perspectives. J Leisure Res 2007, 39(1):109-126.

49. Mactavish $\mathrm{J}$ : Patterns of family recreation in families that include children with a developmental disability. J Leisure Res 1997, 29(1):21-46.

50. Henderson KA, Bialeschki MD, Shaw SM, Freysinger VJ: Both gains and gaps: Feminist perspectives on women's leisure. State College, PA: Venture Publishing; 1996

51. Henderson KA, Dialeschki MD: A sense of entitlement to leisure as constraint and empowerment for women. Leisure Sci 1991, 13(1):51-65.

52. Miller YD, Brown WJ: Determinants of active leisure for women with young children-an "ethic of care" prevails. Leisure Sci 2005, 27(5):405-420

53. Colley A: Sex roles and explanations of leisure behaviour. Leis Stud 1984, 3(3):335-341.

54. Shaw SM: Gender, leisure and constraint: Towards a framework for the analysis of women's leisure. J Leisure Res 1994, 26(1):8-22.

55. Wambach KA: Maternal fatigue in breastfeeding primiparae during the first nine weeks postpartum. J Hum Lact 1998, 14(3):219-229.

56. Gay CL, Lee KA, Lee SY: Sleep patterns and fatigue in new mothers and fathers. Biol Res Nurs 2004, 5(4):311-318.

57. Brown PR, Brown WJ, Miller YD, Hansen V: Perceived constraints and social support for active leisure among mothers with young children. Leisure $\mathrm{SCl}$ 2001, 23(3):131-144.

58. Geraghty SR, Rasmussen KM: Redefining "breastfeeding" initiation and duration in the age of breastmilk pumping. Breastfeed Med 2010, 5(3):135.

59. Rasmussen KM, Geraghty SR: The quiet revolution: breastfeeding transformed with the use of breast pumps. AM J Public Health 2011, 101(8):1356-1359.

60. Fein SB, Mandal B, Roe BE: Success of strategies for combining employment and breastfeeding. Pediatrics 2008, 122(2):S56-S62.

61. Bialeschki MD, Michener S: Re-entering leisure: Transition within the role of motherhood. J Leisure Res 1994, 26:57-57.

62. New J: Autonomy to abandonment: Women's leisure options when confronted by social constraints. Australia: University of Technology, Kuring-gai Campus; 1992.
63. Chatterji P, Frick K: Does returning to work after childbirth affect breastfeeding practices?. Cambridge, MA: National Bureau of Economic Research; 2003:315-335.

64. Kimbro RT: On-the-job moms: Work and breastfeeding initiation and duration for a sample of low-income women. Matern Child Health J 2006, 10(1):19-26.

65. Biagioli F: Returning to work while breastfeeding. Am Fam Physician 2003, 68(11):2201-2208.

doi:10.1186/1471-2458-13-410

Cite this article as: Chow and Dong: Relationship between participation in leisure activities and constraints on Taiwanese breastfeeding mothers during leisure activities. BMC Public Health 2013 13:410.

\section{Submit your next manuscript to BioMed Central and take full advantage of:}

- Convenient online submission

- Thorough peer review

- No space constraints or color figure charges

- Immediate publication on acceptance

- Inclusion in PubMed, CAS, Scopus and Google Scholar

- Research which is freely available for redistribution 